(C) 2005 The Japan Society of Applied Physics

\title{
Characterization of Low-Temperature Stress Hump in Relation to Phase Formation Sequence of Nickel Silicide
}

\author{
Jeong Eui HonG*', Jeong Soo BYUn ${ }^{1}$, Sun Il KIM and Byung Tae AhN \\ Department of Materials Science and Engineering, Korea Advanced Institute of Science and Technology, \\ 373-1Guseong-dong, Yuseong-gu, Daejon 305-701, Korea \\ ${ }^{1}$ Applied Materials Inc., 3050 Bowers Avenue, P.O. Box 58039, Santa Clara, CA 95054-3299, USA
}

(Received August 26, 2004; accepted September 27, 2004; published January 11, 2005)

The stress hump phenomenon observed at a low temperature of approximately $140^{\circ} \mathrm{C}$ during in situ stress-temperature measurement of sputtered Ni thin film on a (001) Si substrate has been investigated. We found that the stress hump was not related to the formation of $\mathrm{NiSi}_{2}$, but originated from the thickening of an amorphous $\mathrm{Ni}-\mathrm{Si}$ intermixing layer in the temperature range of $100-140^{\circ} \mathrm{C}$ followed by the formation of the $\mathrm{Ni}_{2} \mathrm{Si}$ phase at temperatures above $140^{\circ} \mathrm{C}$.

[DOI: 10.1143/JJAP.44.145]

KEYWORDS: NiSi, stress hump, phase formation sequence, interdiffusion

Nickel monosilicide is the most suitable material for the self-aligned silicide process as device geometry is scaled down to the nano regime due to its well-known advantages. $^{1,2)}$ Recently, Lauwers et al. ${ }^{1)}$ and Tsai et $a l .^{3)}$ have reported that the $\mathrm{Ni} / \mathrm{Si}$ system displayed a stress hump at a low temperature, i.e., below $200^{\circ} \mathrm{C}$, which is a unique phenomenon of nickel silicide. Lauwers et al. assumed that this could be related to the formation of epitaxial $\mathrm{NiSi}_{2}$ as the first phase during the annealing of $\mathrm{Ni}$ thin film $(<100 \mathrm{~nm})$ on an implanted (001) Si substrate. A few other authors have also reported the same results. ${ }^{4-6)}$ In this study, we analyzed the microstructures of Ni thin film on a (001) Si substrate with various thermal histories in order to characterize the stress hump in relation to the phase formation sequence.

P-type (001) Si wafers with a resistivity of $5-12 \Omega \mathrm{cm}$ were used as substrates. A $15 \mathrm{~nm}$-thick Ni film was sputterdeposited on the $\mathrm{Si}$ wafers, and followed by $\mathrm{Ti}$ or $\mathrm{TiN}$ capping of $\mathrm{Ni}$ for some of the wafers. Then the wafers were loaded into a vacuum furnace $\left(<3 \times 10^{-6}\right.$ Torr $)$ equipped with a laser beam on top of the chamber. The total force per unit width $(F / W)$ acting on the metal film was in situmeasured during annealing up to $500^{\circ} \mathrm{C}$ at a ramp-up rate of $6^{\circ} \mathrm{C} / \mathrm{min}$. To examine the microstructural changes associated with the low-temperature stress hump, samples were prepared with various thermal histories as described in Table I. X-ray diffraction (XRD) analysis, cross-sectional transmission electron microscopy (TEM), and auger electron spectroscopy (AES) were used for analysis. TEM specimens were made by the focused ion beam (FIB) method to maintain the temperature lower than $100^{\circ} \mathrm{C}$.

Table I. Annealing conditions for microstructural analysis.

\begin{tabular}{cl}
\hline Sample & \multicolumn{1}{c}{ Annealing conditions } \\
\hline a & As-deposited \\
b & Annealed up to $120^{\circ} \mathrm{C}$, then immediately cooled down \\
c & Annealed up to $140^{\circ} \mathrm{C}$, then immediately cooled down \\
d & Annealed up to $140^{\circ} \mathrm{C}$, then held the temperature for 40 min \\
& before being cooled down \\
\hline
\end{tabular}

*E-mail address: jeong_eui_hong@amat.com
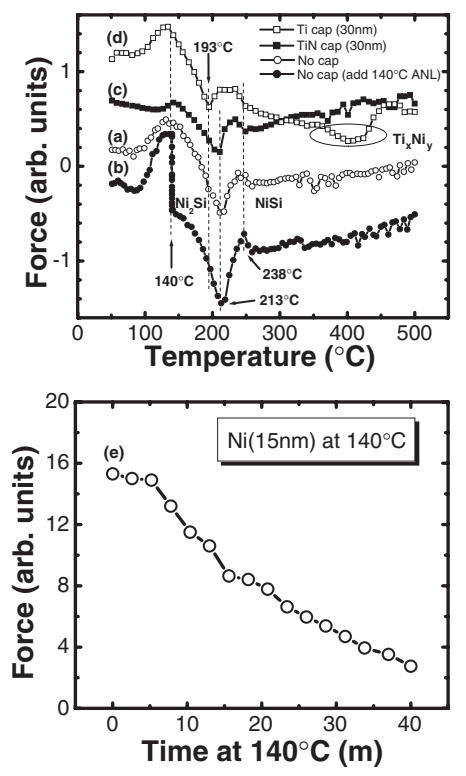

Fig. 1. Total force per unit width $(F / W)$ of Ni $15 \mathrm{~nm} / \mathrm{Si}$; (a) No capping, (b) isothermal annealing step added to uncapped sample, (c) TiN cap, (d) Ti cap, and (e) stress relaxation with time during the isothermal annealing at $140^{\circ} \mathrm{C}$.

Figure 1 shows the $F / W$ acting on the metal film with increasing temperature. For the uncapped wafers in Fig. 1(a), several inflection points are observed at approximately $100^{\circ} \mathrm{C}, 140^{\circ} \mathrm{C}, 210^{\circ} \mathrm{C}$, and $240^{\circ} \mathrm{C}$, corresponding to the formation of $\mathrm{Ni}_{2} \mathrm{Si}$, the phase transformation from $\mathrm{Ni}_{2} \mathrm{Si}$ to $\mathrm{NiSi}$, and the completion of the phase transformation to $\mathrm{NiSi}$, respectively. ${ }^{3)}$ The tensile stress built up in the temperature range of $100-140^{\circ} \mathrm{C}$ was relaxed almost completely during isothermal annealing at $140^{\circ} \mathrm{C}$ [Fig. 1(b)] and the stress relaxation with time was close to linearity [Fig. 1(e)]. For the TiN-capped wafer, only a negligible stress hump is observed at low temperature and the overall variation in $F / W$ is also significantly reduced compared with that of the uncapped wafers due to the rigidity of the TiN film. For the Ti-capped wafer, it is shown that the phase transformation from $\mathrm{Ni}_{2} \mathrm{Si}$ to $\mathrm{NiSi}$ commences at a lower temperature and $F / W$ decreases continuously from $240^{\circ} \mathrm{C}$ to $400^{\circ} \mathrm{C}$, which is presumably related to the formation of the intermetallic compound $\mathrm{Ti}_{x} \mathrm{Ni}_{y}$. 

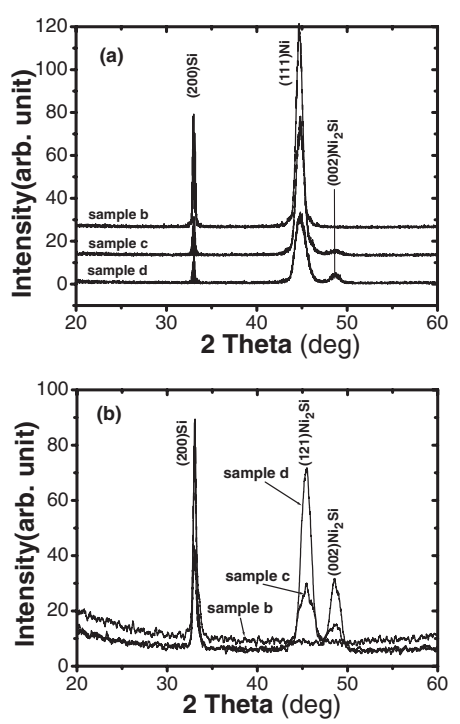

Fig. 2. XRD spectra of Ni $15 \mathrm{~nm} / \mathrm{Si}$ samples before (a) and after Ni stripoff (b).

In Fig. 2, we present the XRD spectra of the samples as functions of annealing conditions. It is shown that the silicide reaction begins at $140^{\circ} \mathrm{C}$ and the first phase is $\mathrm{Ni}_{2} \mathrm{Si}$. Comparing sample $\mathrm{c}$ and sample $\mathrm{d}$, a sharper and stronger $\mathrm{Ni}_{2} \mathrm{Si}$ peak intensity with a decreased $\mathrm{Ni}$ peak was observed for sample d, which implies that more Ni reacted with Si to form $\mathrm{Ni}_{2} \mathrm{Si}$ with increased crystallinity during isothermal annealing at $140^{\circ} \mathrm{C}$. The presence of the $\mathrm{Ni}_{2} \mathrm{Si}$ phase and the difference in the peak intensity of $\mathrm{Ni}_{2} \mathrm{Si}$ between samples $\mathrm{c}$ and $\mathrm{d}$ can be seen more clearly when $\mathrm{Ni}$ is stripped off selectively [Fig. 2(b)]. The formation of $\mathrm{Ni}_{2} \mathrm{Si}$ in this stage is responsible for the decrease in $F / W$ with time at temperatures above $140^{\circ} \mathrm{C}$. After annealing up to $500^{\circ} \mathrm{C}$, only the NiSi phase was present, regardless of the thermal histories (not shown).

Cross-sectional TEM images are presented in Fig. 3. A thin interlayer is observed between $\mathrm{Ni}$ and $\mathrm{Si}$ in samples a and $\mathrm{b}$, which is an amorphous $\mathrm{Ni}-\mathrm{Si}$ mixture with approximately $50 \%$ of each element. ${ }^{7,8)}$ The thicknesses of the amorphous $\mathrm{Ni}-\mathrm{Si}$ mixture in samples a and b were $3.7 \mathrm{~nm}$ and $4.2 \mathrm{~nm}$, respectively. On the other hand, samples $\mathrm{c}$ and $\mathrm{d}$ consist of bilayers of $\mathrm{Ni}$ on top and a mixture of $\mathrm{Ni}_{2} \mathrm{Si}$ and amorphous $\mathrm{Ni}-\mathrm{Si}$ at the interface. While the $\mathrm{Ni}_{2} \mathrm{Si}$ and

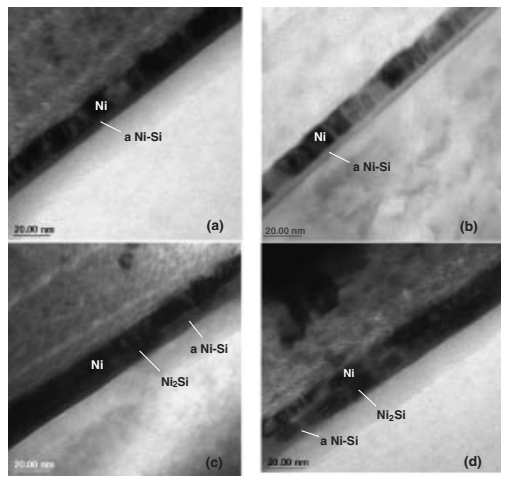

Fig. 3. Cross-sectional TEM images of Ni $15 \mathrm{~nm} / \mathrm{Si}$ samples; (a) sample a, (b) sample b, (c) sample c, and (d) sample d.

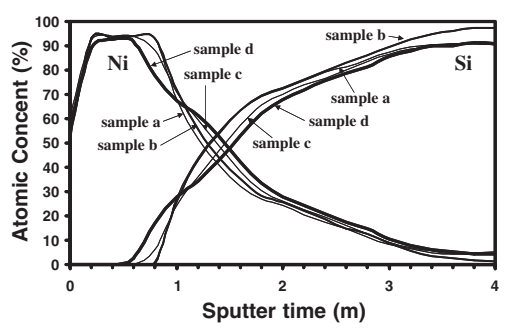

Fig. 4. AES depth profiles of $\mathrm{Ni}$ and $\mathrm{Si}$ atoms in $\mathrm{Ni} 15 \mathrm{~nm} / \mathrm{Si}$ samples as functions of annealing conditions.

amorphous $\mathrm{Ni}-\mathrm{Si}$ layer in sample $\mathrm{c}$ is relatively thin and has amorphous-like contrast, it becomes thicker with more crystalline contrast in sample d [Figs. 3(c) and 3(d)]. Note that there is no faceted interface, which is a typical microstructure of epitaxial $\mathrm{NiSi}_{2}$ on (001) $\mathrm{Si}$ observed in all the samples. It should also be noted that there is no interfacial oxide layer between metals and $\mathrm{Si}$.

Figure 4 shows the AES depth profiles of $\mathrm{Ni}$ and $\mathrm{Si}$ atoms. For sample b, the Ni and Si profiles are almost the same as those of the as-deposited sample except for the slope, which means that $\mathrm{Ni}$ and $\mathrm{Si}$ atoms interdiffused, resulting in a thicker amorphous $\mathrm{Ni}-\mathrm{Si}$ mixture without any silicide reaction during annealing up to $120^{\circ} \mathrm{C}$. On the contrary, samples $\mathrm{c}$ and $\mathrm{d}$ have inflection points in the $\mathrm{Ni}$ and $\mathrm{Si}$ profiles at the point where the atomic concentration ratio of $\mathrm{Ni}$ to $\mathrm{Si}$ is approximately $2: 1$, corresponding to the formation of $\mathrm{Ni}_{2} \mathrm{Si}$. The difference in the $\mathrm{Ni}$ and $\mathrm{Si}$ profiles between samples $\mathrm{c}$ and $\mathrm{d}$ is that $\mathrm{Ni}_{2} \mathrm{Si}$ is thicker in sample $\mathrm{d}$ than in sample $\mathrm{c}$, which is consistent with the observations from XRD and TEM analyses.

In conclusion, we found that the low-temperature stress hump phenomenon observed during in situ stress-temperature measurement of a sputtered $\mathrm{Ni}$ thin film on a (001) Si substrate was not related to the formation of $\mathrm{NiSi}_{2}$, but resulted from the thickening of an amorphous $\mathrm{Ni}-\mathrm{Si}$ intermixing layer caused by interdiffusion of the $\mathrm{Ni}$ and $\mathrm{Si}$ atoms in the temperature range of $100-140^{\circ} \mathrm{C}$. The tensile stress was thereafter relaxed due to the formation of $\mathrm{Ni}_{2} \mathrm{Si}$ as the first phase at temperatures above $140^{\circ} \mathrm{C}$. $\mathrm{Ni}_{2} \mathrm{Si}$ was transformed to $\mathrm{NiSi}$ after annealing up to $500^{\circ} \mathrm{C}$ regardless of the thermal histories.

\section{Acknowledgments}

The Korea Science and Engineering Foundation (KOSEF) financially supported this work.

1) A. Lauwers, A. Steegen, M. de Potter, R. Lindsay, A. Satta, H. Bender and K. Maex: J. Vac. Sci. \& Technol. B 19 (2001) 2026.

2) A. Lawers, P. Besser, T. Gutt, A. Satta, M. de Potter, R. Lindsay, N. Roelandts, F. Loosen, S. Jin, H. Bender, M. Stucchi, C. Vrancken, B. Deweerdt and K. Maex: Microelectron. Eng. 50 (2000) 103.

3) C. J. Tsai and K. H. Yu: Thin Solid Films 350 (1999) 91.

4) L. J. Chen, C. M. Doland, I. W. Wu, J. J. Chu and S. W. Lu: J. Appl. Phys. 62 (1987) 2789.

5) H. Von Kanel: Mater. Sci. Eng. 8 (1992) 196.

6) V. Teodorescu, L. Nistor, H. Bender, A. Steegen, A. Lauwers, K. Maex and J. Can Landuyt: J. Appl. Phys. 90 (2001) 167.

7) G. B. Kim, D.-J. Yoo, H. K. Baik, J.-M. Myoung, S. M. Lee, S. H. Oh and C. G. Park: J. Vac. Sci. \& Technol. B 21 (2003) 319.

8) L. A. Clevenger and C. V. Thompson: J. Appl. Phys. 67 (1990) 1325. 